\title{
The facial profile in brazilian adults
}

\author{
Taísa Figueiredo Chagas ${ }^{1}$, Mariana Martins e \\ Martins $^{2}$, José Nelson Mucha ${ }^{3}$
}

\begin{abstract}
1 MSc Student, Department of Orthodontics, School of Dentistry, Universidade Federal Fluminense, Niterói, Rio de Janeiro, Brazil.

${ }^{2}$ Adjunct professor, Department of Orthodontics, School of Dentistry, Federal Fluminense University, Niterói, Rio de Janeiro, Brazil.

${ }^{3}$ Professor and chair, Department of Orthodontics, School of Dentistry Universidade Federal Fluminense, Niterói, Rio de Janeiro, Brazil.
\end{abstract}

Corresponding author: Taísa Figueiredo Chagas Disciplina de Ortodontia. Faculdade de Odontologia. Rua Mário Santos Braga, $30,2^{\circ}$ andar, sala 214- CEP 24.020-140. Niterói/RJ- Brazil. Tel: (21) 2622-1621 / (21) 2629-9812. chagastaisa@hotmail.com

Received: April 21, 2017

Accepted: September 14, 2017

\begin{abstract}
Aim: To investigate if there is agreement between measurement values obtained for Brazilian adults and the values recommended by Holdaway, Merrifield, Burstone, Steiner and Ricketts, for facial profile soft tissue analysis. Methods: A sample of 30 cephalometric radiographs was used, consisting of 15 women and 15 men, aged 18 to 31 years, all exhibiting excellent occlusion and balanced facial profile. Comparisons were made with the measurement values proposed by the aforementioned authors using Student's t-test and to determine the correlation between the ANB and $\hat{A}-\mathrm{H}$ measurement values described by Holdaway, using Pearson's correlation coefficient. Results: Among the measures evaluated, 4 showed statistically significant differences: Â.Z (Merrifield), S-LS and S-LI (Steiner), and E-LI (Ricketts) relative to the standards recommended by the authors. The measurement values advocated by Merrifield, Steiner and Ricketts showed statistical differences, and as for the Z-angle, Brazilians feature a slightly more convex profile, which appeared slightly concave according to Steiner, and according to the E-Plane (Ricketts), it meant an increased protrusion of the lower lip. Conclusion: It could be asserted that adult Brazilians have a slightly more convex facial profile than US standards, but these differences should be viewed with caution, as they are clinically unimportant.
\end{abstract}

Keywords: Cephalometry; Diagnostic Imaging, Radiography 


\section{Introduction}

Variables such as gender and ethnic origin have different characteristics of skeletal, dental and soft tissue normality, which require knowledge of what is considered normal or standard in each ethnic group ${ }^{1-4}$. In addition, patients expect results to be in accordance with social and cultural standards of beauty prevalent in their reference group, the Zeitgeist, as well as in society in general ${ }^{5}$.

The standards for hard and soft tissues should be considered in establishing a balanced facial aesthetics and an ideal functional occlusion. However, the most widely accepted normative values are based on studies of untreated subjects of European ${ }^{6,7}$, or North American stock ${ }^{8}$

Thus, white Brazilian adults with excellent occlusion might display the position of the lips in the contour of the facial profile in a different relationship from those advocated by various authors for a population of North American or European origin, which would necessarily entail different clinical decisions when planning the orthodontic treatment.

Although the issue has been addressed in the literature, no single work has hitherto evaluated the major facial profile measurements for white Brazilian adults with a balanced facial profile and established an ideal occlusion.

The aim of this study was to investigate if there is agreement between the measurement values obtained for white Brazilian adults and the values recommended by Steiner $^{6}$, Ricketts ${ }^{8}$, Holdaway $^{9}$, Burstone ${ }^{10}$, e Merrifield ${ }^{11}$ for an analysis of facial profile soft tissues. The tested null hypothesis was that there would be no statistically significant difference between the measurement values obtained and the values recommended by these authors.

\section{Material and methods}

Cephalometric measurements of facial profile soft tissues were obtained from 30 cephalometric radiographs from the archives of the Department of Orthodontics, Federal Fluminense University, composed of white Brazilian adults aged 18 to 31 years old with all teeth, in established normal or excellent occlusion and balanced facial profile. The sample comprised 15 women (mean age $=22.67 \pm 3.48$ ) and 15 men (mean age $=23.93 \pm 3.47$ ).

Inclusion criteria were: subjects with all teeth in normal or excellent occlusion and balanced facial profile. Controversial occlusion cases were examined by three orthodontists and removed from the sample, as were patients with a history of trauma and previous orthodontic treatment.

Cephalometric radiographs were taking in natural head position and the cephalograms were traced manually by a single calibrated operator. The anatomical details, points, lines and planes that make up the analysis of soft tissue described by Steiner ${ }^{6}$, Ricketts $^{8}$, Holdaway ${ }^{9}$, Burstone ${ }^{10}$, e Merrifield ${ }^{11}$ and were marked (Figure 1). 

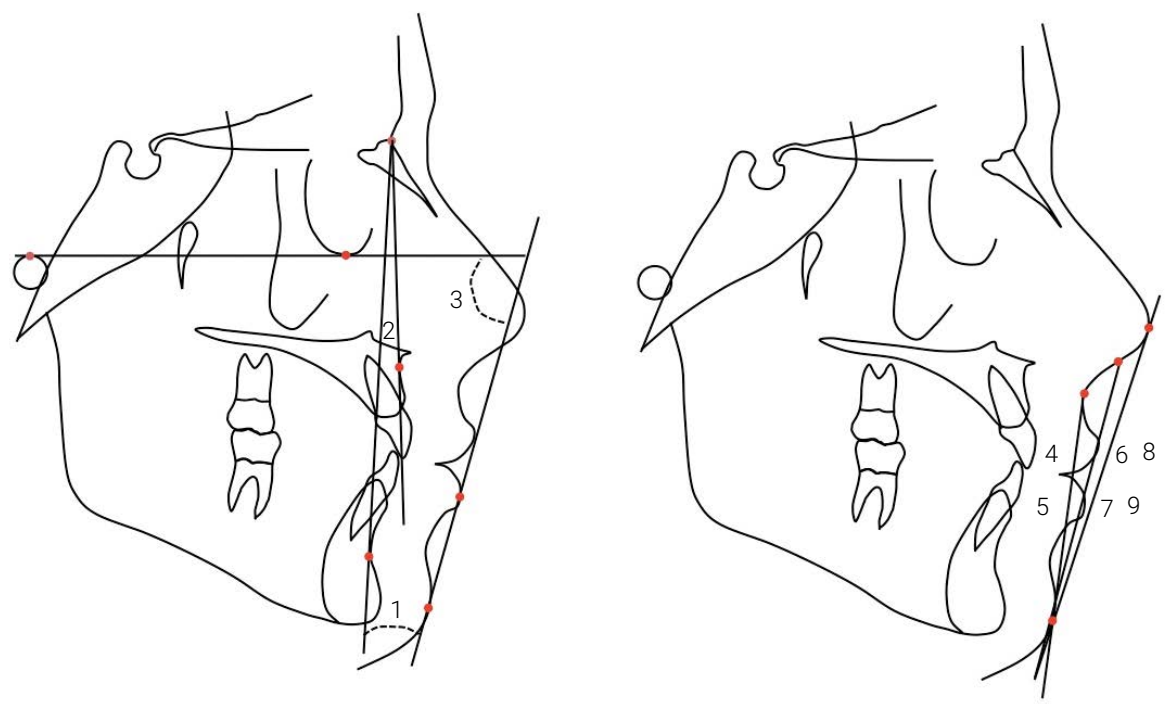

Figure 1. Measures used (1) $\mathrm{H}-$ Angle $^{9}$; (2) ANB angle ${ }^{9}$; (3) Z-Angle ${ }^{11}$; (4) Linear measurement from the most anterior point of the upper lip to the line joining the subnasal and Pogonion points ${ }^{10}$; (5) Linear measurement from the most anterior point of the lower lip to the line joining the subnasal and Pogonion points ${ }^{10}$, (6) Linear measurement from the most anterior point of the upper lip to the line joining the midpoints of the base of the nose to the Pogonion; (7) Linear measurement from the most anterior point of the lower lip to the line joining the midpoints of the base of the nose to the Pogonion ${ }^{6}$; (8) Linear measurement from the most anterior point of the upper lip to the line connecting the tip of the nose and Pogonion points ${ }^{8}$; (9) Linear measurement from the most anterior point of the lower lip to the line joining the tip of the nose and Pogonion points ${ }^{8}$

In order to assess intraexaminer method error measurements from 10 radiographs were evaluated in two stages, with a minimum interval of one week. After the initial evaluation, new tracings were carried out, determining the new points, lines and planes that make up the analysis of the soft tissues proposed for the study. Moreover, intraclass correlation coefficient (ICC) was applied.

The means and variations around the means were obtained and comparisons with the measurement values advanced by the aforementioned authors were made ${ }^{6,8-11}$.

A pilot study was done for the accomplish of sample calculation in which we selected 10 participants randomly, indicating the need to include 30 individuals.

The differences between genders and between ages were compared, and the Shapiro-Wilk test was used to analyze data normality. Student's t-test was applied to those variables whose data distribution was normal in order to compare the means for gender characteristics. The purpose was to determine whether or not sexual dimorphism was present. Furthermore, the Mann-Whitney test was applied to those variables whose data distribution was abnormal.

The mean measurement values found in this study were compared to the values proposed by the authors ${ }^{6,8-11}$ using t-test. The correlation between ANB and $\hat{A}-\mathrm{H}$ measurement values as described by Holdaway ${ }^{9}$ was tested using Pearson's correlation coefficient. 
Biostat 5.3 (Belém, Pará, Brazil) software was employed for statistical analysis and significance level of $5 \%$ was adopted for all tests $(p<0.05)$.

\section{Results}

In evaluating ICC, excellent reproducibility was found in most measures (Â.H, ANB, $\hat{A}-Z$ LB-LS and LB-LI), as well as an average to good reproducibility in 4 other measures (S-LS, S-LI, E-LS and E-LI).

Age in the total sample ranged from 18 to 31 years, with a mean value of 23.30 ( $S D \pm 3.48$ ). In males, the mean value was 23.93 ( $S D \pm 3.47$ ), and in females, 22.67 $(S D \pm 3.48)$, with no statistically significant difference between the groups as a result of the Mann-Whitney test ( $\mathrm{p}$-value $=0.2998$ ).

All individuals included have a balanced facial profile. Twenty eight were skeletal Class I (ANB between 0 and 4.5) and only one take ANB=-1 and another take ANB=5.

Each of the nine measures was evaluated to elicit differences between genders. Distribution was tested by the Shapiro-Wilk test. The five measurements showed abnormal distribution (A-H, LB, LS, LI S-E-E-LS, LI). The Mann-Whitney test was applied to these measurements and independent $t$ test was used for other measurements with normal distribution.

Given that no significant differences were found between the genders, the subgroups were gathered in a single sample group $(n=30)$ and statistical analysis was performed with independent $t$ test (Table 1)

No statistically significant differences were found between the means of the ANB and $\hat{A}$.H measurement values using the parameters provided by Holdaway ${ }^{9}$. The same proved true for the LB-LS and LB-LI mean values using the parameters provided by Burstone ${ }^{10}$.

Table 1. Statistical results for measurement values obtained for white Brazilian adults and the values recommended by authors for an analysis of facial profile soft tissues

\begin{tabular}{|c|c|c|c|c|c|c|c|}
\hline Measure & & Mean (SD) & $\begin{array}{l}\text { Standard } \\
\text { error }\end{array}$ & Range & $\begin{array}{l}\text { Author's } \\
\text { mean }\end{array}$ & $\begin{array}{c}\text { Diferences } \\
\text { between mean } \\
\text { and author's mean }\end{array}$ & $P$ \\
\hline \multirow{2}{*}{ Holdaway } & $\hat{A} . H\left({ }^{\circ}\right)$ & $8.11(2.42)$ & 0.44 & $1.5 / 13.9$ & 8 & 0.11 & 0.7939 \\
\hline & ANB $\left(^{\circ}\right)$ & $1.68(1.17)$ & 0.21 & $-1 / 5$ & 2 & 0.32 & 0.1491 \\
\hline Merrifield & $\hat{A} Z\left(^{0}\right)$ & 77.93 (4.85) & 0.89 & $66 / 89$ & 80 & 2.07 & $0.0267 *$ \\
\hline \multirow{2}{*}{ Burstone } & LB-LS mm & $3.41(1.75)$ & 0.32 & $-2.5 / 6$ & 3.5 & 0.09 & 0.7963 \\
\hline & LB-LI mm & $2.28(1.56)$ & 0.29 & $-1 / 5$ & 2.2 & 0,08 & 0.7761 \\
\hline \multirow{2}{*}{ Steiner } & S-LS mm & $-1.48(1.6)$ & 0.29 & $-5 / 2$ & 0 & -1.48 & $<0.0001$ * \\
\hline & S-LI mm & $-1.01(1.6)$ & 0.29 & $-4 / 1.5$ & 0 & -1.01 & $0.0016^{*}$ \\
\hline \multirow{2}{*}{ Ricketts } & E-LS mm & $-4.85(2.58)$ & 0.48 & $-9 / 5$ & - & - & - \\
\hline & E-LI mm & $-2.78(2.71)$ & 0.50 & $-6 / 5$ & -4 & -1.22 & $0.0203^{*}$ \\
\hline
\end{tabular}

*Significant difference $(p<0.05)$ based on Independent t test 
Holdaway ${ }^{9}$ described a correlation between ANB and $\hat{A}-\mathrm{H}$. Thus, this correlation was tested in this sample using the Pearson correlation coefficient, and a positive $(r=0.4419)$ and significant $(p=0.0144)$ correlation was found. Due to the dependence among these measures a simple linear regression was performed and found the equation: $y=6.5766 x+0.9149 x$, where $y=A . H$ and $x=A N B$.

A statistically significant difference was found between mean Â.Z values in the sample and those provided by Merrifield ${ }^{11}$. Differences were also found between the means of the S-LS and S-LI measurement values compared to the standards provided by Steiner ${ }^{6}$; and between the mean values for E-LI relative to the norms provided by Ricketts ${ }^{8}$.

Only a descriptive analysis of the E-LS was performed since Ricketts ${ }^{8}$ failed to provide a reference value for this measure.

\section{Discussion}

Regarding Holdaway's ${ }^{9}$ analysis, given that statistically significant differences were not observed among the measures of this sample and the above measures, one can consider that the standards and correlations of this analysis can be applied to white Brazilian adults.

For the Z-Angle a mean of 77.93 degrees was found, 2.07 degrees less than the value recommended by Merrifield ${ }^{11}$, suggesting a slightly larger convexity in the profile of white Brazilian adults. Although it is a small difference it proved statistically significant. But clinically, this difference cannot be considered relevant. Leichsenring et al. ${ }^{12}$ found a mean of 71.75 degrees and Yu et al..$^{13}$ found a mean of 68.33 for the Z-Angle in a study conducted with Chinese patients with normal occlusion and balanced profiles, values lower than the 77.93 degrees found in this study. This is probably due to age differences between the samples and can be attributed to the early maturation of girls ${ }^{14}$. It is to be expected that due to mandibular growth there should be an increase in this angle.

In measuring the Subnasal-Pogonion line in the soft tissues relative to the lips ${ }^{10}$ the values for $\mathrm{LB}-\mathrm{LS}=3,41 \mathrm{~mm}$ and $\mathrm{LB}-\mathrm{LI}=2,28 \mathrm{~mm}$, appeared very close to the standards. However, this applied only to adolescents with normal occlusion (LB-LS=3.50 and $L B-L I=2.20)$. One can therefore consider that the measurement values for American teenagers resemble those of Brazilian adults.

The S-LS $(-1,48 \mathrm{~mm})$ and S-LI $(-1.01 \mathrm{~mm})$ measures in this study showed slightly more retruded upper and lower lips compared to the standard established by Steiner ${ }^{6}$. These differences were significant. Moreover, the lower lip protruded more than the upper lip. The differences found in this study can be attributed to the growth of the nose and chin regions, causing the lips to take on a more retruded position relative to this line ${ }^{15}$.

These differences may be explained by ethnic differences in each group. Erbay, Caniklioğlu, Erbay et al. ${ }^{16}$ evaluated 96 Turkish adults aged between 21.63 and 22.45 years, with normal occlusion, and also found lips that were more retruded than the values recommended by Steiner ${ }^{6}$ (women: $\mathrm{S}-\mathrm{LS}=2.7 \mathrm{~mm}$ and $\mathrm{S}-\mathrm{LI}=-2.0 \mathrm{~mm}$, and men S-LS=3.3mm and S-LI=-2.7mm). Isiekwe et al. ${ }^{17}$ in evaluating 100 adult Nige- 
rian individuals (ages 18 to 25 years) with normal occlusion found the values of $\mathrm{S}-\mathrm{LS}=5.89 \mathrm{~mm}$ and S-LI=8.19 $\mathrm{mm}$, indicating lips that were much more protruded than the values established by Steiner. ${ }^{6}$ Sharma ${ }^{18}$ also found upper and lower lips that were more protruded than Steiner's standards ${ }^{6}$ in assessing 121 Nepalis with normal occlusion and well balanced faces (S-LS=2.1 $\mathrm{mm}$ and S-LI=2.2mm).

Regarding the measurement values found for Ricketts' aesthetic plane ${ }^{8}$, the E-LS averaged $-4.85 \mathrm{~mm}$ and could not be compared quantitatively owing to the lack of a reference value. The difference was attributed to the early maturation of girls and their increased nose growth compared to boys. Freitas et al. ${ }^{19}$ also found different results in white Brazilians with normal occlusion (E-LS $=-4.23 \mathrm{~mm}$ ), and although a sample of adolescents was used, the results were similar to those found in this study.

In measuring $\mathrm{E}-\mathrm{LI}$, the mean was $-2.78 \mathrm{~mm}$, with the lower lip positioned $1.22 \mathrm{~mm}$ more anteriorly in relation to the standards established by Ricketts ${ }^{8}$, suggesting that the lower lip in white Brazilian adults is more protruded than advocated by the author, and with a significant difference. Nobuyasu et al. ${ }^{20}$ in evaluating Brazilian individuals aged between 12 and 15 years with normal occlusion also found more protruded lower lips $(-0.95 \mathrm{~mm} \pm 2,37 \mathrm{~mm})$. Freitas et al. ${ }^{19}$ found $-1.96 \mathrm{~mm}$ for $\mathrm{E}-\mathrm{LI}$ in white Brazilian adolescents with normal occlusion. However, the nose and chin positions were not evaluated separately, and those with a more developed nose and chin can provide a good aesthetic appearance due to their greater labial protrusion ${ }^{21}$. Lahlou et al. ${ }^{22}$ also found more retruded upper and lower lips (E-LS=-1.23mm and $E-L I=-0.05 \mathrm{~mm}$ ) after evaluating 102 Moroccan adults with normal occlusion and mean age of 21 years and 6 months.

Cephalometric measurements should not be used strictly for face evaluation and/or clinical examination. Furthermore, extraoral photographic analysis is also extremely important. However, it is still through measurements that we can quantify patient changes and guide our treatment plans.

Neglecting soft tissue analysis and evaluating dental and skeletal relationships separately can produce misleading results since the soft tissues of the face vary in thickness, length and postural tonus in different individuals ${ }^{6}$.

It is important to consider the specific variations in different populations and establish standards for each group, which should be treated according to their own characteristics ${ }^{23}$.

In the present study, a sample group with ages ranging from 18 to 31 years was selected because we wanted to establish an excellent occlusion involving no changes, or at most minimal growth-driven changes in the facial profile so as to allow comparisons to be made. But caution should be exercised in growing patients, and the changes in nose, chin and lip growth should be considered. Nose growth is greater in boys than in girls, and the convexity of the profile soft tissue increases with age, influenced by the position of the nose ${ }^{24}$.

Holdaway's $s^{9}$ was the best analysis for relating the position of the lips with the other structures of the facial profile. Besides, it yielded similar results to this sample. Burstone's ${ }^{10}$ analysis uses an area of stable growth, i.e., the subnasal point, and also showed results that were similar to this sample. 
Although this study was concerned with establishing standards for white Brazilian adults, one should take into account the fact that Brazil is a huge country with an interbred population, making it difficult to establish a single diagnosis and planning standard. One must also take into account each individual's ascendency ${ }^{19,25}$, as there are differences in dentofacial relationship depending on the ethnic variability of each racial group ${ }^{19}$.

This study was concerned with setting standards for white Brazilian adults, and by including only whites, one should take into account the fact that Brazil is a huge country with an interbred population, making it difficult to establish a single diagnosis and planning standard. The authors consider a limitation of this study the fact that the ancenstry of each individual included in the sample was not determined and evaluated as there are differences in the dentofacial relationship depending on the ethnic variability of each racial group ${ }^{19,25}$.

Contemporary orthodontics recognizes the ethnic diversity of human facial contours. However, we still use cephalometric measurements that were designed for specific populations. Thus, the present work contributes to clinical practice as it establishes which cephalometric measures of soft tissue evaluation can be used for white Brazilian adults and which should be evaluated with caution. Even though some of the measurement values presented statistically significant differences compared to the standards or means recommended by different authors one can consider, from a clinical point of view, that the differences were of approximately 1 to $1.5 \mathrm{~mm}$, and that these values are therefore very close to the standards, enabling us to use these measurements as a parameter for white Brazilian adults.

It should also be emphasized that there is a wide variety of facial and ethnic types among individuals seeking treatment to improve the aesthetic appearance of their facial profile, thereby rendering these small differences of little clinical significance.

In conclusion, no statistically significant differences were found between the mean values obtained in this sample and the mean values recommended by Holdaway and Burstone. The measurement values advocated by Merrifield, Steiner and Ricketts showed statistical differences. Nevertheless, regarding the Z-angle, Brazilians feature a more convex profile, which was slightly more concave compared to Steiner's, and showed an increased protrusion of the lower lip compared to the E-Plane (Ricketts). It could be asserted that white Brazilian adults have a slightly more convex facial profile than US standards, but these differences should be viewed with caution, as they are clinically unimportant.

\section{REFERENCES}

1. Tikku T, Khanna R, Maurya RP, Verma S L, Srivastava K.,Kadu, M. Cephalometric norms for orthognathic surgery in North Indian population using Nemoceph software. J Oral Biol Craniofac Res. 2014;4(2):94-103

2. Aldrees AM. Lateral cephalometric norms for Saudi adults: A meta-analysis. Saudi Dent J 2011;23(1):3-7.

3. Haskell BS, Segal ES. Ethnic and ethical challenges in treatment planning: dealing with diversity in the 21st century. Angle Orthod. 2014;84(2):380-2. 
4. Scavone $\mathrm{H}$, Zahn-Silva W, do Valle-Corotti KM, Nahás AC. Soft tissue profile in white brazilian adults with normal occlusions and well-Balanced faces. Angle Orthod. 2008;78(1):58-63.

5. Kiekens RM, Maltha JC, Hof MAT, Kuijpers-Jagtman AM. Objective measures as indicators for facial esthetics in white adolescents. Angle Orthod. 2006;76(4):551-6.

6. Steiner CC. Cephalometrics for you and me. Am J Orthod 1953;39(10):729-55.

7. Tweed $\mathrm{CH}$. The Frankfort mandibular incisal angle (FMIA) in orthodontic diagnosis, treatment planning and prognosis. Angle Orthod 1954;24(3):121-69.

8. Ricketts RM. Esthetics, enviroments, and the law of lip relation. Am J Orthod. 1968;54(4):272-89.

9. Holdaway RA. Soft-tissue cephalometric analysis and its use in orthodontic treatment planning. Am J Orthod. 1983;84(1):1-28.

10. Burstone CJ. Lip posture and its significance in treatment planning. Am J Orthod 1967;53(4):262-84

11. Merrifield LL. The profile line as an aid in critically evaluating facial esthetics. Am J Orthod $1966 ; 52(11): 804-22$

12. Leichsenring A, Invernici S, Maruo IT, Maruo H, Ignácio SA, Tanaka O. Evaluation of the Merrifield’s "Z" angle in the mixed dentition. Rev. de Clín. Pesq. Odontol 2004;1(2):9-14.

13. Yu XN, Bai D, Feng X, Liu YH, Chen WJ, Li S et al. Correlation Between Cephalometric Measures and End-of-Treatment Facial Attractiveness. Journal of Craniofacial Surgery. 2016;27(2), 405-409.

14. Bishara SE, Treder JE, Jakobsen JR. Facial and dental changes in adulthood. Am J Orthod Dentofacial Orthop 1994;106(2):175-86

15. Chaconas SJ; Bratroff JD. Prediction of normal soft-tissue facial changes. Angle Orthod. $1975 ; 45(1): 12-25$

16. Erbay EF, Caniklioğlu CM, Erbay ŞK. Soft tissue profile in Anatolian Turkish adults: Part I. Evaluation of horizontal lip position using different soft tissue analyses. Am J Orthod Dentofacial Orthop 2002;121(1):57-64.

17. Isiekwe GI, Olatokunbo CO, Chukwudi IM. A cephalometric investigation of horizontal lip position in adult Nigerians. J Orthod 2012;39(3):160-9.

18. Sharma JN. Steiner's cephalometric norms for the Nepalese population. J Orthod. 2011;38(1):21-31.

19. Freitas LMAD, Freitas KMSD, Pinzan A, Janson G, Freitas MRD. A comparison of skeletal, dentoalveolar and soft tissue characteristics in white and black Brazilian subjects. J Appl Oral Sci 2010;18(2):135-42.

20. Nobuyasu M, Myahara M, Takahashi T, Attizzani A, Maruo H, Rino W, Carvalho SMRD. Padrões cefalométricos de Ricketts aplicados a indivíduos brasileiros com oclusão excelente. Rev Dental Press Ortod Ortop Facial 2007;12(1):125-56.

21. Czarnecki ST, Nanda RS, Currier GF. Perceptions of a balanced facial profile. Am J Orthod Dentofacial Orthop 1993;104(2):180-7.

22. Lahlou K, Bahoum A, Makhoukhi MB, Aalloula EH. Comparison of dentoalveolar protrusion values in Moroccans and other populations. Eur J Orthod 2010;32(4):430-4.

23. Hwang HS, Kim WS, McNamara Jr JA. Ethnic differences in the soft tissue profile of Korean and European-American adults with normal occlusions and well-balanced faces. Angle orthod 2002; $72(1): 72-80$

24. Chaconas SJ. A statistical evaluation of nasal growth. AmJ Orthod 1969;56(4):403-14.

25. Fernandes TMF, Pinzan A, Sathler R, Freitas MRD, Janson G, Vieira FP. Comparative study of the soft tissue of young Japanese-Brazilian, Caucasian and Mongoloid patients. Dental Press J Orthod. 2013;18(2):116-24. 